\title{
Plasticity of Prefrontal Attention Circuitry: Upregulated Muscarinic Excitability in Response to Decreased Nicotinic Signaling Following Deletion of $\alpha 5$ or $\beta 2$ Subunits
}

\author{
Michael K. Tian, ${ }^{1}$ Craig D. C. Bailey, ${ }^{1}$ Mariella De Biasi, ${ }^{2}$ Marina R. Picciotto, ${ }^{3}$ and Evelyn K. Lambe ${ }^{1,4}$ \\ ${ }^{1}$ Department of Physiology, University of Toronto, Toronto, Ontario M5S 1A8, Canada, ${ }^{2}$ Department of Neuroscience, Baylor College of Medicine, Houston, \\ Texas 77030, ${ }^{3}$ Department of Psychiatry, Yale University School of Medicine, New Haven, Connecticut 06508, and ${ }^{4}$ Department of Obstetrics and \\ Gynaecology, University of Toronto, Toronto, Ontario M5G 1L4, Canada
}

Attention depends on cholinergic stimulation of nicotinic and muscarinic acetylcholine receptors in the medial prefrontal cortex. Pyramidal neurons in layer VI of this region express cholinergic receptors of both families and play an important role in attention through their feedback projections to the thalamus. Here, we investigate how nicotinic and muscarinic cholinergic receptors affect the excitability of these neurons using whole-cell recordings in acute brain slices of prefrontal cortex. Since attention deficits have been documented in both rodents and humans having genetic abnormalities in nicotinic receptors, we focus in particular on how the cholinergic excitation of layer VI neurons is altered by genetic deletion of either of two key nicotinic receptor subunits, the accessory $\alpha 5$ subunit or the ligandbinding $\beta 2$ subunit. We find that the cholinergic excitation of layer VI neurons is dominated by nicotinic receptors in wild-type mice and that the reduction or loss of this nicotinic stimulation is accompanied by a surprising degree of plasticity in excitatory muscarinic receptors. These findings suggest that disrupting nicotinic receptors fundamentally alters the mechanisms and timing of excitation in prefrontal attentional circuitry.

\section{Introduction}

Prefrontal acetylcholine $(\mathrm{ACh})$ release increases with attentional effort (Passetti et al., 2000; Dalley et al., 2004) and correlates with detection of cues on attention tasks (Parikh et al., 2007). The loss of prefrontal ACh afferents, by contrast, substantially lowers cue detection in attention tasks (McGaughy et al., 1996). Attentional processing depends on both ionotropic nicotinic receptors (Bailey et al., 2010; Guillem et al., 2011) and metabotropic muscarinic receptors (Robbins et al., 1998), types of cholinergic receptors that may have synergistic effects (Ellis et al., 2006). The corticothalamic neurons of layer VI are very sensitive to nicotinic stimulation (Kassam et al., 2008; Bailey et al., 2010). These neurons are thought to control the attentional "search light" of the brain through their various feedback projections to the thalamus (Crick, 1984; Zikopoulos and Barbas, 2006; Briggs and Usrey, 2011). Layer VI neurons express the relatively rare $\alpha 5$ nicotinic accessory subunit (Wada et al., 1990; Salas et al., 2003), in addition to the $\alpha 4$ and $\beta 2$ subunits that form the high-affinity

Received July 14, 2011; revised Sept. 22, 2011; accepted Sept. 29, 2011

Author contributions: M.K.T., C.D.C.B., and E.K.L. designed research; M.K.T. and C.D.C.B. performed research; M.D. and M.R.P. contributed unpublished reagents/analytic tools; M.K.T. and E.K.L. analyzed data; M.K.T., C.D.C.B., M.D., M.R.P., and E.K.L. wrote the paper.

This work was supported by grants to E.K.L. from the Canadian Institute of Health Research (MOP 89825), the Canada Research Chairs Program, and the Canadian Foundation for Innovation. M.R.P. was supported by Grants DA14241 and DA10455 from the National Institutes of Health. We thank Dr. Milton Charlton and Dr. Beverley Orser for constructive suggestions on the manuscript.

Correspondence should be addressed to Dr. Evelyn K. Lambe, Department of Physiology, University of Toronto, 1 King's College Circle, Toronto, 0N M5S 1A8, Canada. E-mail: evelyn.lambe@utoronto.ca.

DOI:10.1523/JNEUROSCI.3600-11.2011

Copyright $\odot 2011$ the authors $\quad 0270-6474 / 11 / 3116458-06 \$ 15.00 / 0$ nicotinic receptors. In layer VI neurons, the $\alpha 5$ subunit is incorporated into the $\alpha 4 \beta 2$ subtype of nicotinic receptors, greatly enhancing their conductance (Ramirez-Latorre et al., 1996) and currents (Bailey et al., 2010). Of particular interest, loss of the $\alpha 5$ nicotinic receptors results in attention deficits in mice (Bailey et al., 2010). As layer VI neurons also express muscarinic ACh receptors (Buckley et al., 1988), we investigate the combined effects of nicotinic and muscarinic ACh stimulation on the excitability of these neurons. Since genetic abnormalities in nicotinic receptors are linked to attentional dysfunction (Rigbi et al., 2008; Bailey et al., 2010; Guillem et al., 2011), we examine how the cholinergic excitation of layer VI neurons is altered by genetic deletion of two key nicotinic receptor subunits: the $\alpha 5$ subunit, which increases the conductance of the high-affinity nicotinic receptor, or the $\beta 2$ subunit, which is required for assembly and function of these receptors.

\section{Materials and Methods}

Homozygous mice derived from heterozygous parents were used to generate $\alpha 5\left(\alpha 5^{+/+}\right.$, Salas et al., 2003) and $\beta 2\left(\beta 2^{-/-}\right.$, Picciotto et al., 1995) knock-out mice for experiments. Wild-type (WT) mice were bred in this manner from both $\alpha 5$ and $\beta 2$ lines. Neurons from both WT groups were combined for analysis since no statistically significant differences were observed in our experiments.

Adult male mice from postnatal day (P) 60 to P180 were used to prepare $400-\mu \mathrm{m}$-thick coronal slices of the prefrontal cortex (2.34 to 1.34 $\mathrm{mm}$ anterior to bregma, Paxinos and Franklin, 2001) using a protocol approved by the University of Toronto Animal Care and Use Committee. In brief, the excised brain was cooled with $4^{\circ} \mathrm{C}$ oxygenated sucrose-based ACSF before slicing with a Dosaka Linear Slicer. Slices were transferred to 

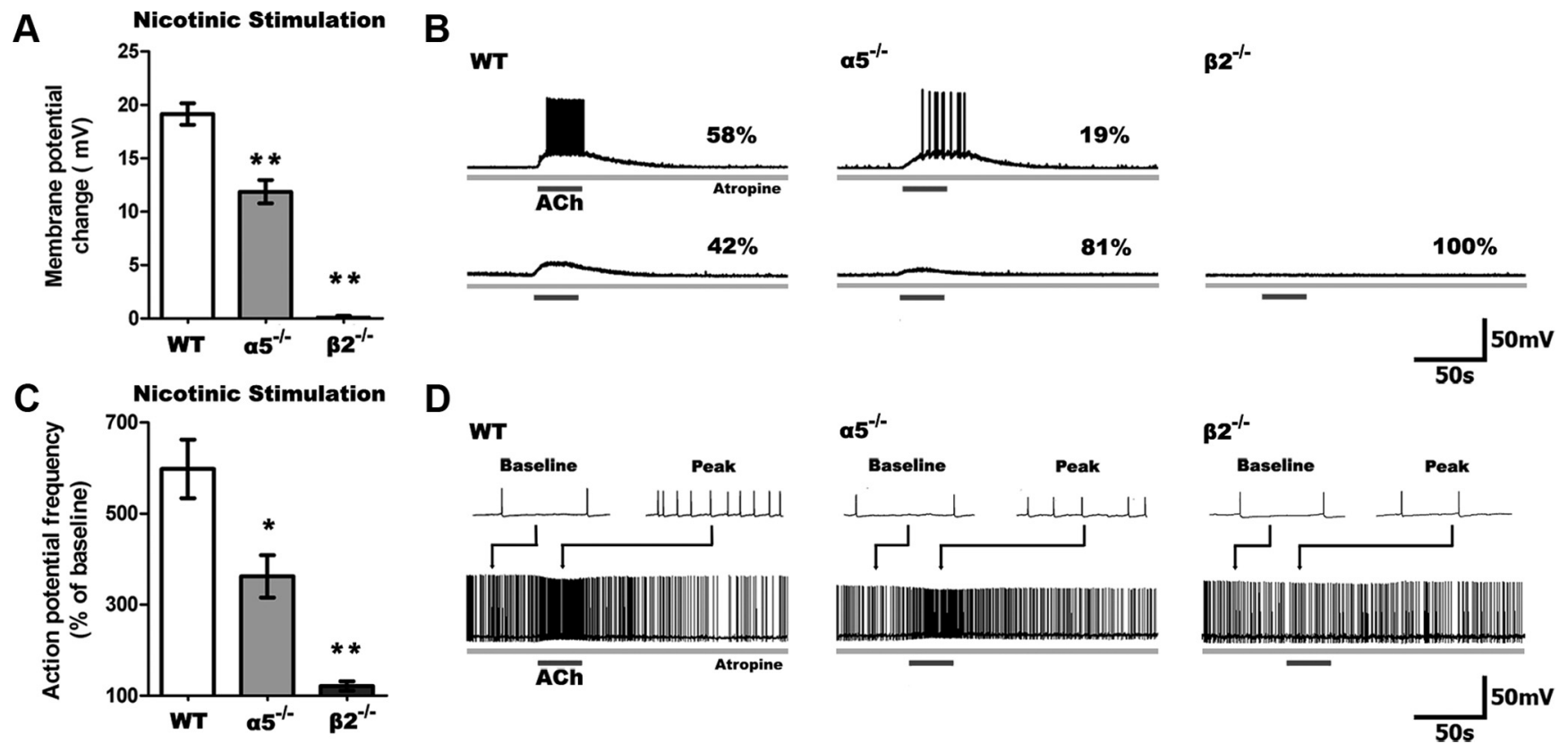

Figure 1. Nicotinic excitability of layer VI pyramidal neurons is reduced in $\alpha 5^{-1-}$ and eliminated in $\beta 2^{-1-}$ mice. A, Stimulation of only nicotinic receptors following blockade of muscarinic receptors by atropine (200 nm) resulted in significant differences in depolarization across all genotypes $(p<0.0001)$, with markedly less depolarization of $\alpha 5^{-/-}$and $\beta 2^{-/-}$compared to WT neurons $\left({ }^{* *} p<0.001\right) . \boldsymbol{B}$, Sample traces show nicotinic responses in neurons across all genotypes, including the percentages of neurons with suprathreshold (top) and subthreshold (bottom) responses. A smaller proportion of neurons were depolarized to threshold in $\alpha 5^{-l-}$ and $\beta 2^{-l-}$ neurons than in WT $\left(\alpha 5^{-l-}: p<0.05, \beta 2^{-\prime-}: p<0.01\right)$. C, In neurons already firing action potentials by current injection, nicotinic stimulation affects spiking frequency differently across genotypes $(p<0.0001)$, with a smaller change in action potential frequency in $\alpha 5^{-1-}$ and $\beta 2^{-I-}$ compared to WT neurons $\left({ }^{*} p<0.05,{ }^{* *} p<0.001\right)$. D, Sample traces show nicotinic responses in neurons depolarized to fire action potentials by current injection. Examples ( $2 \mathrm{~s}$ in duration) of baseline and peak responses are shown above each trace. Data in all figures are shown as mean $\pm \mathrm{SEM}$.

$30^{\circ} \mathrm{C}$ oxygenated ACSF $(128 \mathrm{~mm} \mathrm{NaCl}, 10 \mathrm{~mm}$ D-glucose, $24 \mathrm{~mm}$ $\mathrm{NaHCO}_{2}, 2 \mathrm{~mm} \mathrm{CaCl}_{2}, 2 \mathrm{~mm} \mathrm{MgSO}$, $3 \mathrm{~mm} \mathrm{KCl}, 1.25 \mathrm{~mm} \mathrm{NaH}_{2} \mathrm{PO}_{4} ; \mathrm{pH}$ 7.4). For recordings, slices were placed in a chamber on the stage of an Olympus BX50WI microscope. Oxygenated ACSF at room temperature flowed over the slice at $3-4 \mathrm{ml} / \mathrm{min}$.

Electrophysiology. Pipettes (3-4 M $\Omega$ ) containing 120 mм K-gluconate, $5 \mathrm{~mm} \mathrm{KCl}, 2 \mathrm{~mm} \mathrm{MgCl}_{2}$, 4 mм K $\mathrm{K}_{2}$-ATP, $0.4 \mathrm{~mm} \mathrm{Na}_{2}$-GTP, $10 \mathrm{~mm} \mathrm{Na}_{2}$ phosphocreatine, and 10 mm HEPES buffer (adjusted to $\mathrm{pH} 7.3$ with $\mathrm{KOH}$ ) were used to patch layer VI pyramidal neurons in prelimbic cortex (Paxinos and Franklin, 2001). These neurons were conservatively selected based on their proximity to white matter $(<200 \mu \mathrm{m}$; Alves et al., 2010) together with known morphological distinguishing features of layer VI (on average, the pyramidal neurons are smaller and closer together than in layer $\mathrm{V}$ ). Neurons were recorded in current clamp using an EPC10 (HEKA) and corrected for the liquid junction potential.

Across the genotypes, there were no significant differences in resting potential $\left(F_{(2,177)}=0.43, p=0.6\right)$, input resistance $\left(F_{(2,177)}=1.2, p=\right.$ $0.3)$, or spike amplitude $\left(F_{(2,177)}=1.6, p=0.2\right)$. Recordings were made either at resting membrane potential or with current injected to elicit a steady $\sim 1 \mathrm{~Hz}$ action potential firing at baseline. ACh-induced depolarizations were measured relative to the resting potential. Changes in action potential frequency were determined using Clampfit software (Molecular Devices) by comparing the rate of firing over a $30 \mathrm{~s}$ period during the peak of the $\mathrm{ACh}$ response to that at baseline. As a control experiment, a pharmacologically identified subgroup of layer VI pyramidal neurons was selected based on their response to hypocretin (Bayer et al., 2004). There were no significant differences in cell properties between neurons responsive to hypocretin and the general population of layer VI pyramidal neurons.

Pharmacology. We probed cholinergic currents by applying $1 \mathrm{~mm}$ ACh to the bath after a period of baseline recording. Either atropine (200 nM), or a combination of $\mathrm{DH} \beta \mathrm{E}(3 \mu \mathrm{M})$ and MLA $(10 \mathrm{nM})$ were applied in ACSF to examine nicotinic and muscarinic effects, respectively. No antagonists were used in cholinergic experiments examining combined nicotinic and muscarinic effects. The subset of experiments testing responses to hypocretin $2(100-300 \mathrm{~nm})$, in addition to ACh, were con- ducted at $32^{\circ} \mathrm{C}$ (Bayer et al., 2004). All compounds were obtained from Sigma, Phoenix Pharmaceuticals, or Tocris Bioscience.

Statistical analysis. Effects of ACh on membrane potential, rate of action potential firing, and the kinetics of these responses were assessed for all genotypes with one-way ANOVAs, as were comparisons of cell properties across genotypes. We used Fisher's exact tests to evaluate genotype differences in the proportions of neurons depolarized to threshold by ACh. Unpaired $t$ tests were used to compare components of the ACh response. The effect of atropine on the muscarinic response was analyzed by paired $t$ test. The interaction between nicotinic and muscarinic effects across genotypes was analyzed by two-way ANOVA, and the difference within each genotype was assessed with Bonferroni post hoc tests.

\section{Results}

Nicotinic excitability in layer VI is reduced in $\alpha 5^{-/-}$mice and eliminated in $\boldsymbol{\beta} 2^{-/-}$mice

First, we examined the nicotinic depolarization of layer VI pyramidal neurons in WT, $\alpha 5^{-/-}$, and $\beta 2^{-/-}$mice since these subunits are known to be the principal constituents of the nicotinic receptors expressed in this layer along with the $\alpha 4$ subunit. In the presence of atropine $(200 \mathrm{~nm})$ to block muscarinic receptors, stimulation with ACh (1 mM, $15 \mathrm{~s})$ resulted in significantly different depolarization across the genotypes $\left(F_{(2,49)}=47.89, p=\right.$ $0.0001)$. As illustrated in Figure 1, ACh depolarized layer VI neurons in WT mice to the greatest extent $(n=24)$, depolarized $\alpha 5^{-/-}$neurons to a lesser degree $(n=21)$, and did not alter the membrane potential in $\beta 2^{-l-}$ neurons $(n=7)$. Nicotinic excitation was sufficient to elicit action potentials in the majority of WT neurons, fewer $\alpha 5^{-l-}$ neurons $(p<0.05)$, and none of the $\beta 2^{-l-}$ neurons.

To examine nicotinic effects on the excitability of alreadydepolarized neurons, we injected neurons with positive current to elicit action potentials $(\sim 1 \mathrm{~Hz})$ at baseline. The current required did not differ significantly across genotypes, consistent 


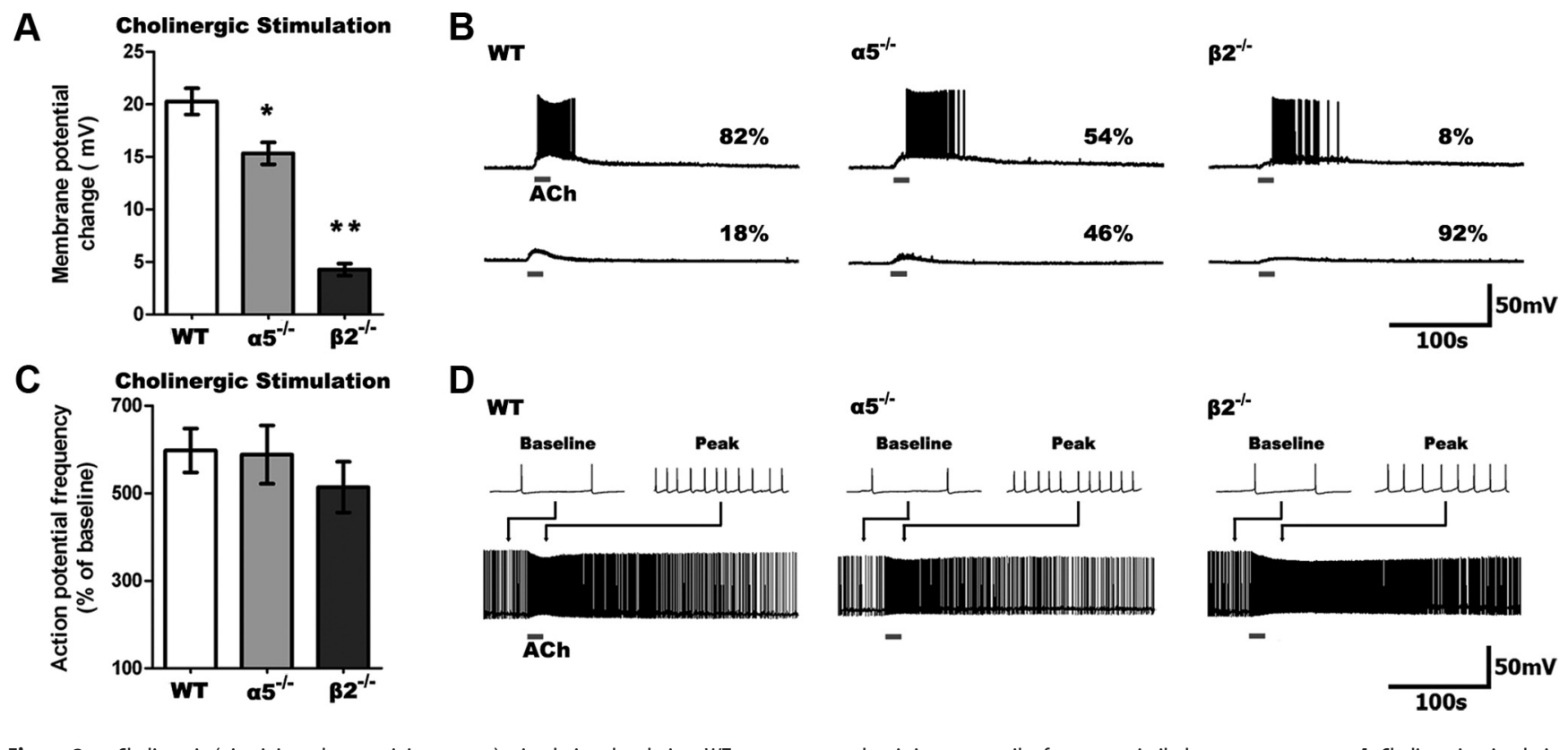

Figure 2. Cholinergic (nicotinic and muscarinic receptor) stimulation depolarizes WT neurons most, but it increases spike frequency similarly across genotypes. $A$, Cholinergic stimulation depolarizes neurons to a different degree across genotypes $(p<0.0001)$, with less depolarization in $\alpha 5^{-/-}$and $\beta 2^{-1-}$ compared to WT neurons $\left({ }^{*} p<0.01,{ }^{* *} p<0.001\right)$. B, Sample traces showing cholinergic responses in neurons of all genotypes. C, Cholinergic stimulation increases action potential firing frequency to a similar degree across all genotypes $(p=0.5)$. D, Sample traces showing cholinergic responses in neurons of all genotypes depolarized to fire action potentials by current injection. $\boldsymbol{B}, \boldsymbol{D}$, Note the slower onset and prolonged peak response in $\beta 2^{-/-}$neurons.

with the lack of significant difference in input resistance. As illustrated in Figure $1 C$, ACh increased the frequency of action potential firing in a genotype-dependent manner $\left(F_{(2,31)}=11.78\right.$, $p=0.0002)$. This treatment resulted in a large increase in the firing frequency of WT $(n=15)$ and $\alpha 5^{-l-}$ neurons $(n=14)$ but not $\beta 2^{-1-}$ neurons $(n=5)$.

Cholinergic excitation of layer VI cortical neurons primarily involves nicotinic receptors unless nicotinic drive is impaired The striking differences across genotypes in the response to nicotinic stimulation raised the question of how layer VI neurons normally respond to ACh in the absence of atropine, when it can stimulate both nicotinic and muscarinic receptors together. This experiment is shown in Figure 2 (we use "cholinergic" to identify conditions where both nicotinic and muscarinic receptors are stimulated). In layer VI neurons from WT mice, we find that cholinergic depolarization does not differ greatly from nicotinic depolarization alone (cholinergic: $20.3 \pm 1.3 \mathrm{mV}, n=23$; nicotinic: $19.2 \pm 1.0 \mathrm{mV}, n=24 ; t=0.7, p=0.5)$. By contrast, layer VI neurons from $\alpha 5^{-/-}$mice show greater depolarization when both nicotinic and muscarinic receptors are stimulated (cholinergic: $15.3 \pm 1.1 \mathrm{mV}, n=26$; nicotinic: $11.9 \pm 1.1 \mathrm{mV}, n=21$; $t=2.2, p=0.03)$. More strikingly in $\beta 2^{-1-}$ mice, the muscarinic component appears dominant since the response to nicotinic stimulation is negligible in comparison with the response to cholinergic stimulation (cholinergic: $4.3 \pm 0.6 \mathrm{mV}, n=23$; nicotinic: $0.1 \pm 0.2 \mathrm{mV}, n=7 ; t=3.8, p=0.0005)$. Yet, there are significant differences in the magnitude of depolarization elicited by cholinergic stimulation across the genotypes $\left(F_{(2,69)}=63.12, p=\right.$ $0.0001)$. Compared to nicotinic stimulation alone, cholinergic stimulation had a significantly greater effect on the ability to elicit action potentials from rest in neurons from $\alpha 5^{-1-}$ mice, and was able to elicit spiking in some neurons from $\beta 2^{-1-}$ mice.

In contrast to the differences in nicotinic effects in layer VI neurons across genotypes, cholinergic stimulation increased the frequency of action potential firing similarly across all three groups. As illustrated in Figure 2C, we observed no significant differences in the percentage increase in action potential frequency at the peak of the cholinergic response between layer VI neurons from WT $(n=22), \alpha 5^{-1-}(n=17)$, and $\beta 2^{-1-}(n=24)$ mice $\left(F_{(2,60)}=0.67, p=0.5\right)$. The similar effects of ACh across genotypes on spike frequency cannot be attributed to a ceiling effect, since injected depolarizing current was consistently able to elicit faster spiking across the genotypes (paired $t$ test, $n=59, t=$ 20.7, $p<0.0001$ ).

Notably, the time course of cholinergic effects was genotype dependent, with slower onset and substantially longer currents in layer VI neurons from $\beta 2^{-1-}$ mice. The $10-90 \%$ rise times of cholinergic responses in $\beta 2^{-/-}$mice were slower for depolarization (WT: $13.3 \pm 1.1 \mathrm{~s}, \alpha 5^{-l-}: 14.7 \pm 0.6 \mathrm{~s}, \beta 2^{-l-}: 25.8 \pm 2.9 \mathrm{~s}$; $F_{(2,45)}=10.1, p=0.0002 ; p<0.01$ for WT vs $\left.\beta 2^{-l-}\right)$ and action potential frequency (WT: $14.6 \pm 0.8 \mathrm{~s}, \alpha 5^{-/-}: 13.4 \pm 1.3 \mathrm{~s}$, $\left.\beta 2^{-l-}: 20.7 \pm 2.6 \mathrm{~s} ; F_{(2,42)}=4.1, p=0.02\right)$. Yet, the peak cholinergic effects lasted much longer in $\beta 2^{-/-}$neurons, as shown by the $\tau$ (63\% decay time) of depolarization (WT: $53.0 \pm 8.3 \mathrm{~s}$, $\alpha 5^{-l-}: 53.4 \pm 9.2 \mathrm{~s}, \beta 2^{-l-}: 257.3 \pm 22.8 \mathrm{~s} ; F_{(2,45)}=48.3, p<$ $0.0001 ; p<0.001$ for WT vs $\beta 2^{-1-}$ ) and action potential frequency (WT: $42.7 \pm 4.4 \mathrm{~s}, \alpha 5^{-/-}: 56.1 \pm 10.8 \mathrm{~s}, \beta 2^{-/-}: 111.6 \pm 25.5 \mathrm{~s}$; $F_{(2,38)}=5.5, p<0.01 ; p<0.01$ for WT vs $\left.\beta 2^{-/-}\right)$.

Muscarinic responses are enhanced in layer VI of $\alpha 5^{-/-}$and $\boldsymbol{\beta 2 ^ { - 1 - }}$ compared to WT mice

The difference between responses to nicotinic-only and total cholinergic stimulation in layer VI neurons of $\alpha 5^{-/-}$and $\beta 2^{-/-}$ mice suggests potential plasticity in muscarinic-only ACh effects. To address this question, we tested the effects of muscarinic-only stimulation using $\mathrm{ACh}$ in the presence of nicotinic blockers (DH $\beta \mathrm{E} 3 \mu \mathrm{M}$, MLA $10 \mathrm{nM}$ ), as well as antagonists for the AMPA and NMDA glutamate receptors (CNQX $10 \mu \mathrm{M}$, APV $50 \mu \mathrm{M}$ ) to assess whether functional upregulation of muscarinic currents occurred in layer VI neurons lacking specific nicotinic receptor subtypes. Changes in membrane potential following muscarinic 
A
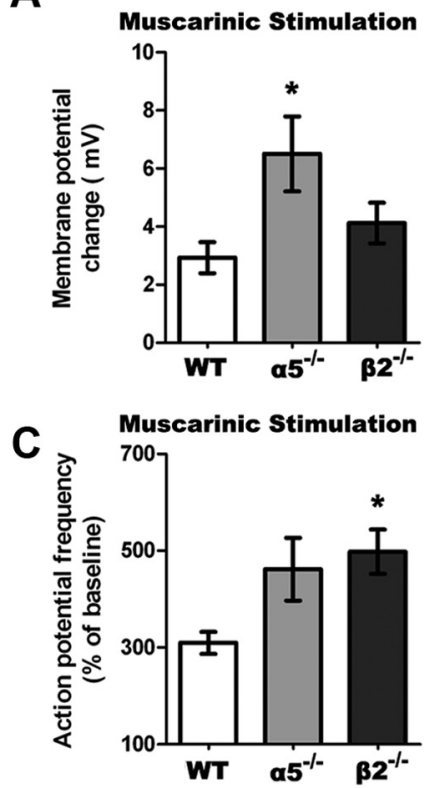

B WT

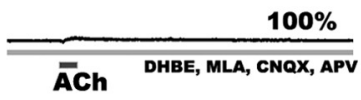

D

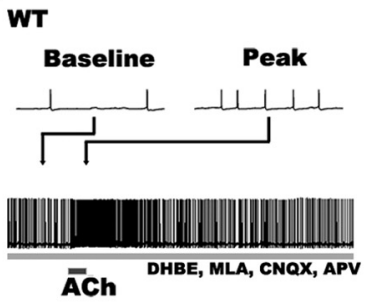

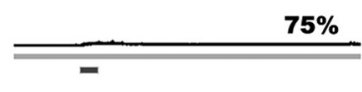

$\alpha 5^{-1-}$

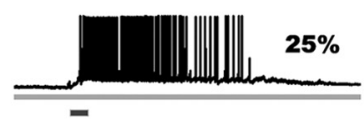

$\mathbf{7 5 \%}$

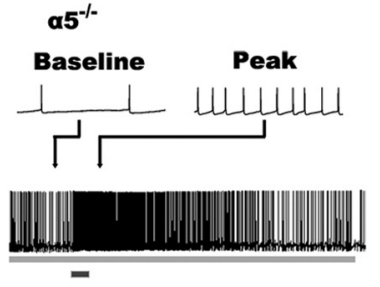

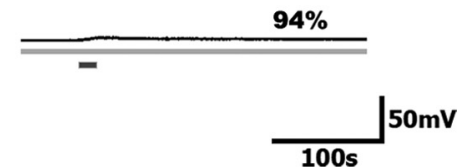

$\boldsymbol{\beta 2}^{-/-}$

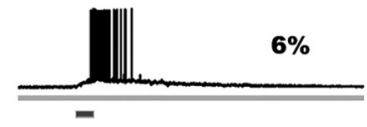

100s

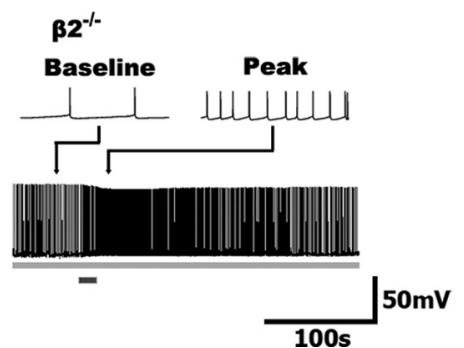

Figure 3. Muscarinic responses are enhanced in $\alpha 5^{-I-}$ and $\beta 2^{-I-}$ compared to WT neurons. $A$, Stimulation of only muscarinic receptors on layer VI neurons following blockade of nicotinic receptors ( $3 \mu \mathrm{m}$ DHBE, $10 \mathrm{~nm} \mathrm{MLA}$ ) and glutamate receptors (10 $\mu \mathrm{m}$ CNQX, $50 \mu \mathrm{M}$ APV) resulted in significant differences in depolarization across genotypes $(p<0.05)$, with greater muscarinic depolarization seen in $\alpha 5^{-I-}$ than WT neurons ( ${ }^{*} p<0.05$ ). B, Sample traces show the muscarinic response in neurons from all genotypes. No WT neurons, but some $\alpha 5^{-/-}$and $\beta 2^{-/-}$neurons are depolarized to threshold. C, Muscarinic stimulation increases action potential firing differently across the genotypes $(p<0.001)$, with action potential frequency increasing to a greater degree in $\beta 2^{-/-}$compared to WT neurons ( $\left.{ }^{*} p<0.05\right)$. D. Sample traces showing muscarinic responses in neurons depolarized to fire action potentials by current injection.

stimulation were significantly different across the genotypes $\left(F_{(2,47)}=4.20, p=0.02\right)$, as illustrated in Figure 3. The elicited depolarization in layer VI neurons from WT mice were small $(n=17)$ compared to the larger depolarization in those from $\alpha 5^{-1-}(n=16 ; t=2.6, p=0.01)$ and $\beta 2^{-1-}(n=17)$ mice. The muscarinic antagonist atropine $(200 \mathrm{nM}, 10 \mathrm{~min})$ suppressed these responses in all genotypes $(n=11, t=3.4, p=0.006)$. Furthermore, selective antagonists for the excitatory M1 and M3 muscarinic receptors (pirenzepine, $500 \mathrm{nm;} \mathrm{J-104129} \mathrm{fumarate,}$ $50 \mathrm{~nm}$ ) almost completely suppressed the depolarization (22 \pm $17 \%$ of that seen previously; $n=5$ ).

There were also significant genotype differences in the increase in firing frequency elicited by muscarinic stimulation $\left(F_{(2,46)}=3.86, p=0.03\right)$. Muscarinic stimulation increased peak action potential firing in layer VI neurons from WT mice $(n=$ 14 ), but this increase was significantly larger in layer VI neurons from both $\alpha 5^{-1-}(n=16 ; t=2.1, p=0.04)$ and $\beta 2^{-l-}(n=19$; $t=3.3, p=0.002)$ mice. Again, these muscarinic responses were suppressed by atropine across the genotypes $(n=7, t=6.5, p=$ 0.0006). Similarly, M1/M3 antagonists completely eliminated the increase in action potential firing $(-5 \pm 6 \%$ of that seen previously, $n=7$ ).

With muscarinic-only stimulation, all three genotypes showed the longer $10-90 \%$ rise times and $\mathrm{T}$ characteristic of responses mediated only by G-protein-coupled receptors. These results contrast with the kinetics of the cholinergic responses where the fast, nicotinic responses dominated in the WT and $\alpha 5^{-l-}$ mice, and the slow, muscarinic response dominated in the $\beta 2^{-1-}$ mice.

Hypocretin-responsive layer VI neurons show same pattern of muscarinic responses

The differences in the magnitude of the muscarinic responses across the genotypes raises the question of whether the layer VI
A

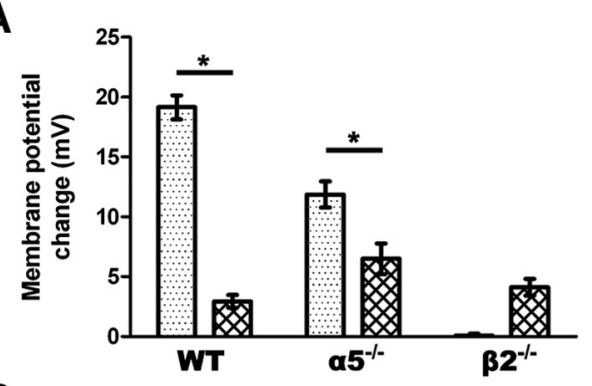

B

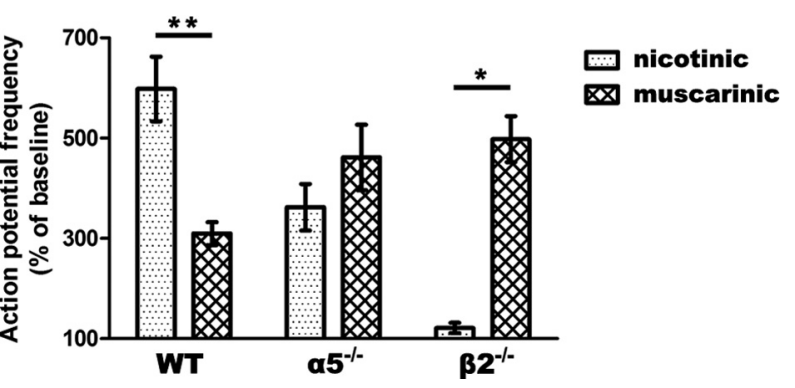

Figure 4. The balance of nicotinic to muscarinic excitation is shifted in $\alpha 5^{-/-}$and $\beta 2^{-/-}$ compared to WT neurons. $A$, There is a significant interaction in the degree of nicotinic and muscarinic depolarization across genotypes $(p<0.0001)$. Nicotinic stimulation contributes more to membrane depolarization in WT and $\alpha 5^{-1-}$ neurons $\left({ }^{*} p<0.01\right)$. B, A significant interaction is found in the increase in action potential firing by nicotinic versus muscarinic stimulation across genotypes $(p<0.0001)$. Nicotinic stimulation increases spiking frequency to a greater degree in WT neurons, while muscarinic stimulation makes a larger contribution in $\beta 2^{-1-}$ neurons $\left({ }^{*} p<0.01,{ }^{* *} P<0.001\right)$.

neurons in the mice deleted for nicotinic subunits are indeed the same type of neurons as in WT mice. To address this question, we examined a pharmacologically identified subgroup of neurons within layer VI of cortex (Bayer et al., 2004). In these neurons 
excited by hypocretin (100-300 $\mathrm{nm}, 1 \mathrm{~min}$ ), which were recorded at $32^{\circ} \mathrm{C}$ (based on Bayer et al., 2004), muscarinic responses showed the same pattern across genotypes as in the previous room temperature recordings of the general population of layer VI neurons (change in membrane potential: WT, $2.5 \pm 0.6 \mathrm{mV}$, $n=9 ; \alpha 5^{-l-}, 8.7 \pm 2.3 \mathrm{mV}, n=9 ; \beta 2^{-l-}, 7.9 \pm 1.4 \mathrm{mV}, n=13$; $F_{(2,28)}=4.2, p=0.02$; change in spiking frequency: WT, $341 \pm$ $94 \%, n=9 ; \alpha 5^{-l-}, 763 \pm 160 \%, n=9 ; \beta 2^{-/-}, 651 \pm 113 \%, n=$ $\left.10 ; F_{(2,25)}=2.9, p=0.07\right)$. These findings are consistent with the interpretation that layer VI neurons, which normally display large nicotinic responses to $\mathrm{ACh}$, upregulate their muscarinic responses after loss or reduction of nicotinic excitation. To ascertain the specificity of this M1/M3 muscarinic upregulation, we compared the response to hypocretin across the genotypes since it is also mediated by a $\mathrm{G} \alpha_{\mathrm{q}}$-coupled receptor. However, these responses did not differ by genotype $\left(F_{(2,82)}=0.85, p=0.4\right)$.

\section{The balance of muscarinic to nicotinic excitation differs across genotypes}

Differences in the responses to nicotinic and muscarinic stimulation across genotypes are illustrated in Figure 4. Analysis of changes in membrane potential shows a strong interaction between the responses to nicotinic and muscarinic stimulation $\left(F_{(2,96)}=41.75, p=0.0001\right)$ (Fig. $\left.4 A\right)$, with the genotypes varying greatly in the ratio of the muscarinic to the nicotinic response (WT: $0.2, \alpha 5^{-1-}: 0.6, \beta 2^{-1-}: 61$ ). As illustrated in Figure $4 B$, we observed a similar interaction in the increase in action potential frequency due to nicotinic and muscarinic stimulation $\left(F_{(2,77)}=\right.$ $15.4, p=0.0001$, with the genotypes varying substantially in the ratio of the muscarinic to the nicotinic response (WT: $0.5, \alpha 5^{-1-}$ : $\left.1.3, \beta 2^{-/-}: 4.1\right)$. There appears to be a negligible contribution of muscarinic receptors in WT mice, a balance between nicotinic and muscarinic contributions in $\alpha 5^{-/-}$, and a predominant contribution of muscarinic receptors in $\beta 2^{-1-}$ mice.

\section{Discussion}

We have found that ACh predominantly excites layer VI pyramidal neurons in WT mice through nicotinic receptors. Impairment in nicotinic stimulation through genetic deletion of either the conductance-enhancing $\alpha 5$ subunit or the ligand-binding $\beta 2$ subunit is accompanied by an increase in the cholinergic excitation of these neurons through the metabotropic muscarinic family of ACh receptors. This muscarinic excitation is suppressed by antagonists of M1 and M3 receptors and significantly alters the timing of the peak cholinergic response in mice deleted for the ligand-binding $\beta 2$ subunit. Our results suggest that disrupting nicotinic receptor function can fundamentally alter the mechanisms and timing of excitation in prefrontal attentional circuitry.

Humans and rodents with aberrant expression or function of nicotinic receptors are at higher risk for attention deficits (Rigbi et al., 2008; Bailey et al., 2010; Guillem et al., 2011). Such changes in nicotinic receptors can result from genetic polymorphisms that reduce function (Bierut et al., 2008; Kuryatov et al., 2011) or through developmental exposure to the drug nicotine (Poorthuis et al., 2009). The observed upregulation of the typically smaller muscarinic component of cholinergic activation in neurons of $\alpha 5^{-/-}$and $\beta 2^{-l-}$ mice allows a substantial response to ACh despite the reduction or loss of nicotinic receptor function, and highlights the functional significance of nicotinic signaling within attention pathways. Our results suggest that humans with reduced prefrontal nicotinic receptor function may have a larger muscarinic contribution toward the overall cholinergic response in layer VI neurons. This plasticity of cholinergic signaling may, in fact, reduce the apparent severity of the attention deficits resulting from genetic or developmental alterations in nicotinic receptors. Indeed, in mice performing an attention task, $\alpha 5^{-1-}$ mice show only significantly lower accuracy compared to WT controls under challenging conditions (Bailey et al., 2010), while $\beta 2^{-/-}$mice demonstrate only a higher level of omissions but no decreases in accuracy (Guillem et al., 2011). Yet, having an atypical muscarinic component, which is slower and longer than the normal nicotinic excitation, may result in more complex changes to prefrontal attention circuitry and function than previously anticipated.

Our results indicate that synergistic effects of prefrontal nicotinic and muscarinic receptors on attentional performance (Ellis et al., 2006) do not normally reflect shared activation of layer VI neurons. Instead, these receptors may act predominantly on different cortical output layers. In mice with genetically induced nicotinic dysfunction, we observed increased excitatory muscarinic responses in layer VI neurons that act in a homeostatic manner to preserve their cholinergic response. However, our results suggest that this atypical muscarinic excitability of layer VI neurons is not uniformly upregulated. The ACh depolarization from rest is only partially rescued, yet the increase in action potential frequency of already-depolarized neurons appears completely normal. Since cortical muscarinic receptor binding is not altered in $\beta 2^{-1-}$ mice (Zoli et al., 1999), the differential rescue of two aspects of cortical excitability suggests a locus of plasticity downstream of the muscarinic receptors.

The medial prefrontal cortex and its cholinergic afferents are essential for efficient attentional processing. Here, we show that the cholinergic excitation of layer VI neurons is of sufficient functional importance that compensatory processes provide this excitation even in the absence of the nicotinic receptors normally responsible in WT mice. While the upregulation of muscarinic excitability may ameliorate the severity of attention deficits resulting from alterations in nicotinic receptors, it would likely alter the speed of attentional processing and render layer VI attention circuitry vulnerable to the effects of anti-muscarinic medications.

\section{References}

Alves NC, Bailey CD, Nashmi R, Lambe EK (2010) Developmental sex differences in nicotinic currents of prefrontal layer VI neurons in mice and rats. PLoS One 5:e9261.

Bailey CD, De Biasi M, Fletcher PJ, Lambe EK (2010) The nicotinic acetylcholine receptor $\alpha 5$ subunit plays a key role in attention circuitry and accuracy. J Neurosci 30:9241-9252.

Bayer L, Serafin M, Eggermann E, Saint-Mleux B, Machard D, Jones BE, Mühlethaler M (2004) Exclusive postsynaptic action of hypocretinorexin on sublayer $6 \mathrm{~b}$ cortical neurons. J Neurosci 24:6760-6764.

Bierut LJ, Stitzel JA, Wang JC, Hinrichs AL, Grucza RA, Xuei X, Saccone NL, Saccone SF, Bertelsen S, Fox L, Horton WJ, Breslau N, Budde J, Cloninger CR, Dick DM, Foroud T, Hatsukami D, Hesselbrock V, Johnson EO, Kramer J, et al. (2008) Variants in nicotinic receptors and risk for nicotine dependence. Am J Psychiatry 165:1163-1171.

Briggs F, Usrey WM (2011) Corticogeniculate feedback and visual processing in the primate. J Physiol 589:33-40.

Buckley NJ, Bonner TI, Brann MR (1988) Localization of a family of muscarinic receptor mRNAs in rat brain. J Neurosci 8:4646-4652.

Crick F (1984) Function of the thalamic reticular complex: the searchlight hypothesis. Proc Natl Acad Sci U S A 81:4586-4590.

Dalley JW, Cardinal RN, Robbins TW (2004) Prefrontal executive and cognitive functions in rodents: neural and neurochemical substrates. Neurosci Biobehav Rev 28:771-784.

Ellis JR, Ellis KA, Bartholomeusz CF, Harrison BJ, Wesnes KA, Erskine FF, Vitetta L, Nathan PJ (2006) Muscarinic and nicotinic receptors synergistically modulate working memory and attention in humans. Int J Neuropsychopharmacol 9:175-189. 
Guillem K, Bloem B, Poorthuis RB, Loos M, Smit AB, Maskos U, Spijker S, Mansvelder HD (2011) Nicotinic acetylcholine receptor $\beta 2$ subunits in the medial prefrontal cortex control attention. Science 333:888-891.

Kassam SM, Herman PM, Goodfellow NM, Alves NC, Lambe EK (2008) Developmental excitation of corticothalamic neurons by nicotinic acetylcholine receptors. J Neurosci 28:8756-8764.

Kuryatov A, Berrettini W, Lindstrom J (2011) AChR alpha5 subunit variant associated with risk for nicotine dependence and lung cancer reduces (alpha4beta2)2alpha5 AChRs function. Mol Pharmacol 79:119-125.

McGaughy J, Kaiser T, Sarter M (1996) Behavioral vigilance following infusions of 192 IgG-saporin into the basal forebrain: selectivity of the behavioral impairment and relation to cortical AChE-positive fiber density. Behav Neurosci 110:247-265.

Parikh V, Kozak R, MartinezV, Sarter M (2007) Prefrontal acetylcholine release controls cue detection on multiple timescales. Neuron 56:141-154.

Passetti F, Dalley JW, O'Connell MT, Everitt BJ, Robbins TW (2000) Increased acetylcholine release in the rat medial prefrontal cortex during performance of a visual attentional task. Eur J Neurosci 12:3051-3058.

Paxinos G, Franklin KBJ (2001) The mouse brain in stereotaxic coordinates. San Diego: Academic.

Picciotto MR, Zoli M, Léna C, Bessis A, Lallemand Y, Le Novère N, Vincent P, Pich EM, Brûlet P, Changeux JP (1995) Abnormal avoidance learning in mice lacking functional high-affinity nicotine receptor in the brain. Nature 374:65-67.

Poorthuis RB, Goriounova NA, Couey JJ, Mansvelder HD (2009) Nicotinic actions on neuronal networks for cognition: general principles and longterm consequences. Biochem Pharmacol 78:668-676.

Ramirez-Latorre J, Yu CR, Qu X, Perin F, Karlin A, Role L (1996) Functional contributions of alpha5 subunit to neuronal acetylcholine receptor channels. Nature 380:347-351.

Rigbi A, Kanyas K, Yakir A, Greenbaum L, Pollak Y, Ben-Asher E, Lancet D, Kertzman S, Lerer B (2008) Why do young women smoke? V. Role of direct and interactive effects of nicotinic cholinergic receptor gene variation on neurocognitive function. Genes Brain Behav 7:164-172.

Robbins TW, Granon S, Muir JL, Durantou F, Harrison A, Everitt BJ (1998) Neural systems underlying arousal and attention. Implications for drug abuse. Ann N Y Acad Sci 846:222-237.

Salas R, Orr-Urtreger A, Broide RS, Beaudet A, Paylor R, De Biasi M (2003) The nicotinic acetylcholine receptor subunit alpha 5 mediates short-term effects of nicotine in vivo. Mol Pharmacol 63:1059-1066.

Wada E, McKinnon D, Heinemann S, Patrick J, Swanson LW (1990) The distribution of mRNA encoded by a new member of the neuronal nicotinic acetylcholine receptor gene family (alpha 5 ) in the rat central nervous system. Brain Res 526:45-53.

Zikopoulos B, Barbas H (2006) Prefrontal projections to the thalamic reticular nucleus form a unique circuit for attentional mechanisms. J Neurosci 26:7348-7361.

Zoli M, Picciotto MR, Ferrari R, Cocchi D, Changeux JP (1999) Increased neurodegeneration during aging in mice lacking high-affinity nicotine receptors. EMBO J 18:1235-1244. 